\title{
Reseña: El tránsito hacia el Estado Nacional en América Latina en el siglo XIX: Argentina, México y Colombia'
}

\author{
Constanza Amézquita Quintana²
}

\begin{abstract}
a obra del profesor Pérez Rivera en su conjunto constituye una aproximación al conocimiento de la formación del Estado Nacional en América Latina, su enfoque es sociológico y tiene como objeto identificar las particularidades económicas, políticas y culturales que configuraron la centralización del poder y la evolución de la economía en la región. Se trata de un estudio comparativo del desarrollo del Estado Nacional en tres países: Argentina, México y Colombia, durante el siglo XIX, que toma en cuenta los elementos constitutivos de un Estado Nacional ideal, que son: la formación del mercado interno, la fragmentacióncentralización, el monopolio de la violencia física y el sentimiento nacional.
\end{abstract}

El autor encuentra que el tipo de Estado Nacional emergente en cada uno de los tres países estudiados, casi setenta años después de la independencia, mantiene hacia 1880 una semejanza de orden teórico general con el Estado europeo occidental. Asimismo, plantea que dicho fenómeno fue posible gracias a la dinámica económica que llevó a la conformación del mercado interno a finales del siglo XIX y a la dinámica política de centralización del poder y de implantación de las bases para la unidad nacional por parte de gobiernos autoritarios. Sobre estos pivotes se entreteje el análisis a lo largo de los tres capítulos en los que está dividida la obra.

El autor señala que durante la primera mitad del siglo XIX Argentina, México y Colombia afrontaron un período de estancamiento económico debido al empleo de técnicas agropecuarias rudimentarias y a la existencia generalizada de latifundios improductivos en medio de su dependencia de la agricultura. También la escasa población, la débil infraestructura de transporte y la excesiva carga de impuestos coloniales tomaron parte en aquel estancamiento. Sólo hasta la segunda mitad del siglo XIX surgieron algunas innovaciones tecnológicas y aumentaron los grados de desarrollo de las fuerzas productivas y de división del trabajo. Esto dinamizó el comercio así como el cultivo y la exportación de productos agrícolas. De igual forma, se dio un incremento en la población, que en el caso argentino, cabe destacar, se debió a los elevados volúmenes de inmigrantes europeos. $^{3}$ 
Pese a ello, en los tres países el esquema de la propiedad de la tierra en pocas manos se mantuvo y los terratenientes poco llegaron a diferenciarse de los comerciantes. Como resultado -expone el profesor Pérez Rivera-: a finales del siglo XIX la propiedad de la tierra estaba concentrada en pocas manos en los tres países. En Argentina y México hubo un considerable número de extranjeros en los sectores agrícola y comercial, además de un alto grado de crecimiento de sus exportaciones. Entretanto, la economía colombiana se caracterizó por haber girado en torno al ahorro nacional y muy poco o casi nada en torno a la inversión extranjera.

El autor muestra el modo en que Argentina, México y Colombia debieron afrontar las tensiones centro-periferia, bajo la forma de resistencias ante la imposición de una capital a las demás provincias de las nacientes repúblicas. En los primeros dos países las tensiones tuvieron marcadas diferencias económicas, sociales y culturales que dieron lugar a una fragmentación económica y social. Por el contrario, en Colombia el conflicto centro-periferia no cobró mayores dimensiones, en especial debido a cuatro factores: primero, la menor extensión del territorio colombiano; segundo, la interacción regional en virtud del tráfico comercial; tercero, el reconocimiento de la diversidad provincial por parte de la élite liberal-conservadora en la legislación federalista colombiana; y cuarto, la mayor importancia que adquirieron los atributos de clase en las relaciones sociales frente a las identidades regionales.

Al respecto, se observa que la fragmentación social que tuvo lugar a propósito del conflicto centro-periferia cobró especiales dimensiones en México donde la población se dividió en dos partes por razones étnicas. La parte mayoritaria, indígena, fue excluida del fundamento de la nación. Por el contrario, en Colombia predominó el mestizaje desde la época colonial. Sin embargo, la homogeneidad que este propició no constituyó un elemento de unidad nacional en nuestro país, debido a las condiciones de atraso del mismo y al aislamiento de las regiones, además de la temprana constitución del bipartidismo como barrera para el desenvolvimiento de una conciencia nacional.

El profesor Pérez examina el caso de los caudillos militares que surgieron en los tres países, como consecuencia de la fragmentación de poderes regionales, que tuvo lugar luego de la independencia, especialmente en Argentina y México. Señala que en Colombia, un país caracterizado por su tradición civilista, también surgieron caudillos militares, pero estos actuaron respetando la ley fundamental de la organización del Estado, sin buscar instaurar un régimen autoritario como el de Rosas en Argentina (1829-1831 y 1835-1852) o el de Santa Ana en México (quien asumió el poder 10 veces entre 1830 y 1854).

El autor encuentra que fue hacia 1880, cuando tres líderes carismáticos actuaron como los principales agentes de los cambios en la estructura de dominación de los tres países. Se refiere a Julio Roca en Argentina (1880-1886, 1898-1904), a Porfirio Díaz en México (1877-1880 y 1884-1911) y a Rafael Núñez en Colombia (elegido cuatro veces presidente entre 1880 y 1894). De los dos primeros destaca su condición de jefes militares, mientras que de Núñez exalta su condición de jefe civilista a saber, un abogado. Pese a ello, todos recurrieron a la violencia física para quebrantar la anterior estructura de dominación. Mientras Díaz lo hizo a través de la insurrección, los otros dos obtuvieron la presidencia por elección popular. Roca solo logró posesionarse tras derrotar al ejército de Buenos Aires y Núñez debió enfrentar el levantamiento armado de los radicales y vencerlos para lograr la unidad nacional.

Cabe destacar, como lo señala Pérez Rivera, que estos líderes carismáticos carecieron de articulación directa con los intereses de los grupos sociales y que el Estado fue 
independiente frente a estos. Roca contó con el apoyo del ejército de las provincias confederadas y de miembros de la élite política argentina para llegar al poder; Porfirio Díaz se apoyó en las armas y en los intelectuales llamados "los científicos"; mientras Rafael Núñez tuvo el respaldo de una coalición bipartidista de liberales independientes y del sector "nacionalista" del partido conservador, agrupados en el partido nacional.

Los tres líderes mencionados creían tanto en los principios liberales de organización del Estado como en la necesidad de centralizar el poder del mismo. Sin embargo, cuando se instalaron en el poder volvieron hacia la tradición, combinando su arbitrio personal en las decisiones con cierta adaptación a las normas de cálculo racional características del desarrollo capitalista. De esta forma, por ejemplo, mientras los dirigentes financiaban el crecimiento de la burocracia, que tuvo lugar durante la segunda mitad del siglo XIX, con la ampliación del comercio y de la agricultura capitalista, nombraban a los funcionarios por su condición de servidores personalmente vinculados a ellos. Con esto, le imprimían rasgos patrimoniales al Estado. Adicionalmente, estos líderes auspiciaron que una minoría tomara el monopolio de la tierra y que la naciente burguesía mercantil se incorporara al privilegiado estamento encabezado por los terratenientes.

De acuerdo con el autor, el componente "nacional" del Estado a finales del siglo XIX era precario en los tres países. Tan sólo en Colombia se presentó un alto grado de homogeneidad del pueblo en torno al idioma español, debido al predominio del mestizaje y a la escasa población indígena, que en su mayor parte adoptó el español antes de la independencia. Entretanto, en Argentina y México el uso del español se limitó a una parte de la población y se percibió el anclaje en un pasado distinto al heredado de España. Adicionalmente, en Colombia el bipartidismo neutralizó el desarrollo de un sentimiento nacional. Con respecto a la religión católica, aunque era mayoritaria en los tres países, fue excluida de la órbita del poder. En Colombia recibió algunas ventajas con la Constitución de 1886, a diferencia de lo ocurrido en Argentina y México, donde se afianzó el proceso de secularización iniciado a mediados de siglo.

Pérez Rivera concluye que las élites políticas de Argentina, México y Colombia, se propusieron desde los comienzos de la independencia realizar el ideal liberal de sociedadeuropeay norteamericana.Todoello sobre la base de una estructura económicosocial heredada de la colonia, en la cual primaban la pobreza, la dependencia de la agricultura, el estancamiento económico y las disparidades regionales. El autor logra evidencia histórica de cómo hacia la década de 1870 los tres países transitaron hacia el Estado Nacional, gracias a la formación de una burocracia moderna y al surgimiento de nuevos movimientos políticos que instauraron un Estado fuerte, que erradicó la fragmentación y abrió el camino hacia la unidad nacional. Sin embargo, los tres países llegaron únicamente al desarrollo de un Estado administrativo y fiscal en el que Estado y Nación aún no podían ser entendidos como sinónimos.

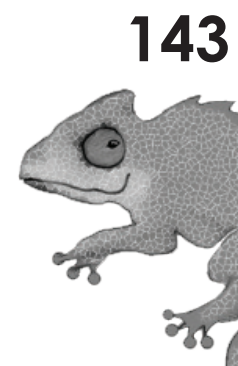




\section{Libros Recomendados}
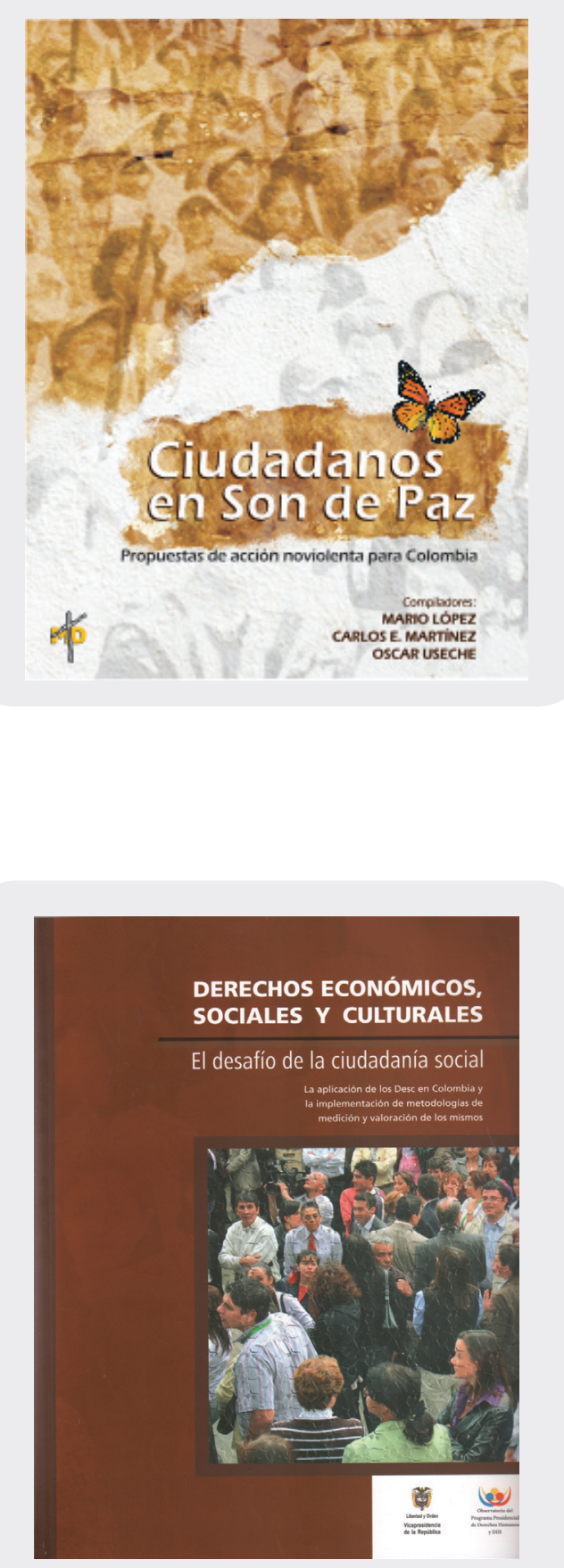

\section{CIUDADANOS EN SON DE PAZ}

Comp.: Mario López, Carlos E. Martínez y Oscar Useche Año: 2008

Este libro es un aporte a los estudios sobre las acciones noviolentas en Colombia y en algunos otros países, de esas prácticas de rebeldía y afirmación vital que van emergiendo con la fuerza moral y política que les otorga el demostrar concordancia entre métodos y finalidades, y que requieren de análisis sistemáticos de los procesos por donde han transitado y de los resultados que han obtenido, hasta ahora invisibilizados por los discursos dominantes.

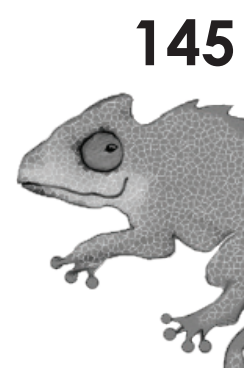

DERECHOS ECONÓMICOS, SOCIALESY CULTURALES. El desafío de la ciudadanía social

Autor: Oscar Useche Aldana

Año: 2009

Este libro es resultado de una investigación financiada por el Observatorio del Programa Presidencial de Derechos Humanos y DIH, de la Vicepresidencia de la República de Colombia y desarrollo de las dimensiones ética, política y social que entraña la perspectiva de derechos y la necesidad de construir unos indicadores en DESC y un sistema de información pública en clave de derechos. 